Volume 6

\title{
A Unifying Framework to Study Workplace Decision-Making Aptitude and Performance
}

\author{
Nikki Blacksmith \\ Consortium Research Fellows Program, Consortium Universities of the Washington Metropolitan Area \\ Maureen E. McCusker \\ Consortium Research Fellows Program, Consortium Universities of the Washington Metropolitan Area \\ Theodore L. Hayes \\ George Washington University
}

Follow this and additional works at: https://scholarworks.bgsu.edu/pad

Part of the Human Resources Management Commons, Industrial and Organizational Psychology

Commons, and the Other Psychology Commons

How does access to this work benefit you? Let us know!

\section{Recommended Citation}

Blacksmith, Nikki; McCusker, Maureen E.; and Hayes, Theodore L. (2020) "A Unifying Framework to Study Workplace Decision-Making Aptitude and Performance," Personnel Assessment and Decisions: Number 6 : Iss. 2 , Article 8.

DOI: https://doi.org/10.25035/pad.2020.02.008

Available at: https://scholarworks.bgsu.edu/pad/vol6/iss2/8

\section{(c) (i)}

This work is licensed under a Creative Commons Attribution 4.0 International License.

This Main Article is brought to you for free and open access by the Journals at ScholarWorks@BGSU. It has been accepted for inclusion in Personnel Assessment and Decisions by an authorized editor of ScholarWorks@BGSU. 


\title{
A Unifying Framework to Study Workplace Decision-Making Aptitude and Performance
}

\author{
Nikki Blacksmith', Maureen E. McCusker', and Theodore L. \\ Hayes $^{2}$ \\ 1. Consortium Research Fellows Program, Consortium Universities of the \\ Washington Metropolitan Area \\ 2. Organizational Sciences and Communication, George Washington University
}

\section{KEYWORDS}

decision making, individual differences, aptitude, latent profile analysis, latent class analysis
ABSTRACT

Employers are facing a skills shortage in the labor market: there are not enough workers who can perform the complex decision-making tasks that characterize 21 st-century work. This manuscript aims to stimulate research investigating the relationship among individual differences, decision-making aptitude, and decision performance. We offer guidelines for future research by laying out a framework to unify disparate streams of research from organizational science, and judgment and decision-making research. We advocate for the use of pattern-oriented analytical approaches to capture the complexities of the predictor and criterion space.
Employers are facing what is being referred to as the "global skills shortage" or "global skills crisis" (e.g., Hays, 2018; IBM, 2016; Schumann, 2018; Society for Human Resource Management, 2019) that is worsening over time, impacting productivity growth at individual, organizational, and societal levels (Industrial Strategy Council, 2019; McLaren, 2018). For example, in 2018, the U.S. reported seven million job openings, but only 6.3 million unemployed workers (skilled and unskilled) were available to fill them (SHRM, 2019). By 2030, this global skills shortage could cost organizations across the globe trillions of dollars (Korn Ferry, 2018; McLaren, 2018).

Leaders consistently rank decision-making capacity at the top of the list of skills in shortage across the globe (Bakhshi et al., 2017; Industrial Strategy Council, 2019). According to a report from McKinsey Global Institute (2018), the demand for effective decision making will grow at cumulative, double-digit rates in the United States and Europe through 2030. Accordingly, some of the world's largest organizations, including Google, Starbucks (Schneider, 2017; Tsipursky, 2018), and the Department of Defense (e.g., National Research Council, 2015), are seeking solutions to the shortage of skilled workers, presenting an opportunity for organizational scientists to offer support to leaders.

The judgment and decision making (JDM) literature has generated an abundance of knowledge about decision processes and task characteristics that define how people make decisions (Bazerman \& Moore, 2013; Beach, 1996; Byrnes, 2011; Driskell \& Salas, 1991; Hastie \& Dawes, 2001; Highhouse et al., 2014). Much less is known about the predictors involved in high-performance decision-making behavior in organizations (Dalal \& Brooks, 2014; Mohammed \& Schwall, 2009; Oreg \& Bayazit, 2009), particularly the role of individual differences in the process. The lack of research provokes two key questions: (a) Why do people make the decisions they make, and (b) to what extent do these differences stem from individual differences?

It is critical to understand the complexity of individual differences in decision-making capacity because findings can help develop organizational leaders' and employees' decision-making skills. However, the research conducted to

\footnotetext{
Corresponding author:

Nikki Blacksmith

Consortium Research Fellows Program, Consortium Universities of the Washington Metropolitan Area

4214 King Street, First Floor, Alexandria, VA 22302

Email: nikkiblacksmith@gmail.com
}

Disclaimer: The research described herein was sponsored by the U.S. Army Research Institute for the Behavioral and Social Sciences, Department of the Army (Cooperative Agreement No. W911NF-16-2-0092). The views expressed in this presentation are those of the authors and do not reflect the official policy or position of the Department of the Army, DOD, or the U.S. Government. 
date in this area (e.g., Appelt et al., 2011; Shanteau, 1992; Starcke \& Brand, 2012) is fragmented, lacking the unifying framework necessary to inform practical interventions.

The purpose of this manuscript is twofold. First, we outline a conceptual, theoretically based framework for decision-making aptitude and performance that unites an otherwise fragmented body of research. Drawing from selection and job performance theory, we explain how we can begin to integrate and unify research findings from JDM with organizational science. We offer a cross-disciplinary approach to provoke scientific research that investigates the complex relationships among individual differences, decision-making aptitude, and decision performance. The second purpose of this paper is to advocate for methodological and analytical tools novel to the decision-making field. We describe the power that mixture modeling techniques grant researchers in integrating much of what we know from prior literature and allowing researchers to approach individual differences and decision making from a holistic perspective. Taking a holistic approach allows researchers to capture the complexity of the decision-making process. We argue that this unifying framework and corresponding methodological recommendations give organizational scientists considerable promise to advance workplace decision-making research and practice that reduces the decision-making skills shortage in the labor market.

\section{A Unifying Framework}

Researchers can expand the understanding of decision-making aptitude by examining the role individual differences play in the decision-making process and decision-making behaviors by using the same approach typically used in employee selection and job performance research. We advocate for this approach because decision making is a narrow dimension of job performance (Campbell \& Wiernik, 2015; Dalal \& Brooks, 2014). Because they are a dimension of job performance, any cognitive or behavioral actions associated with workplace decision-making processes are, by definition, performance behaviors. Fortunately, more than a century's worth of selection research exists to further understand decision-making aptitude (Binning \& Barrett, 1989; Ryan \& Ployhart, 2014; Sackett et al., 2017) and develop a useful framework to unify the fragmented literature.

\section{Defining Decision Making as a Dimension of Job Perfor- mance}

There are two critical steps involved in understanding, explaining, and predicting any type of performance in the workplace: (a) conceptualizing the criterion domain and (b) mapping predictors onto the criterion. The first step is to conceptualize the criterion domain, which, in this case, is decision-making (job) performance. Job performance is defined as behaviors that contribute to organizational goals (Borman et al., 1997; Borman et al., 2014; Campbell et al., 1996; Guion, 2011). Performance theory states that job performance can be specified by defining the behaviors needed to enact the tasks that contribute to organizational goals (Campbell et al., 1996; Sonnentag \& Frese, 2002). Thus, if defining job performance starts with defining the key behaviors enacted to perform the tasks, then we can use descriptive decision-making research to define the fundamental behaviors enacted to perform the decision tasks.

Myriad decision models and paradigms from prior JDM research can be useful for identifying the key performance behaviors and building the conceptualization of workplace decision-making performance (Highhouse et al., 2014). Below we briefly discuss prominent findings from JDM research, not with the intent of comprehensively reviewing the literature (c.f., Weber \& Johnson, 2009) but rather to explain how the findings can be integrated into organizational research to conceptualize decision-making performance and its nomological network.

A significant focus in JDM research has sought to understand how people make decisions. Findings detail a common set of behaviors in which people engage when making decisions, which can be used to define the decision-making performance domain (Hastie \& Dawes, 2001; Weber \& Johnson, 2009). We know the general process and fundamental behaviors of decision making include initiating action, gathering information, generating and assessing options, and assigning value to outcomes (Anderson, 1971; Beach, 1996; Hastie \& Dawes, 2001; Mitchell, 2017; Weber \& Johnson, 2009). When people make decisions, they rely on both intuitive (unconscious) and deliberate (conscious) thought processes (Evans, 2008). Other cognitive functions, such as attention, perception, and memory retrieval, also play roles in the decision-making process (Lachter et al., 2004; Simon, 1978). Collectively, this body of research shows that human beings are limited in their capacity to intake, encode, remember, and process information (i.e., we have bounded rationality; Simon, 1955, 1978), and therefore, are inherently flawed decision makers.

Another focus driving much of JDM science is how people should make decisions. Within this body of research, rationality - defined by axiomatic principles of logic and probability - is deemed the optimal approach to decision making (Hastie \& Dawes, 2001). Poor decision making is marked by deviations from normative or optimal choices (Hastie \& Dawes, 2001). Kahneman and colleagues (Kahneman, 2011; Kahneman \& Tversky, 1979; Tversky \& Kahneman, 1974) identified a set of mental shortcuts (cognitive heuristics) that lead to irrational or poor choices. For example, when in the information gathering stage, people often seek information that confirms their existing beliefs, referred to as confirmation bias (e.g., Harvey \& Woodruff, 2013). Reliance on cognitive heuristics, however, also has 
advantages; in some situations, it can improve decision making, particularly when decisions need to be made rapidly, and there is no time to deliberate (Gigerenzer \& Gaissmaier, 2011).

A third focus has been on investigating which situational factors influence decision making and to what extent they influence how a person makes a decision. Naturalistic decision-making approaches seek to understand the environmental factors that influence decision making, including pressure, time constraints, complexity, and expertise in nonexperimental, "real-world" decision-making environments (Klein, 2008; Klein \& Klinger, 1991). Also of central concern is determining which strategies people use when making decisions in high-uncertainty, high-stakes, and unstable conditions (Klein, 2008). Decision characteristics (e.g., level of complexity), types (e.g., tactical, strategic, hiring), and organizational characteristics (e.g., cultural norms) all influence decision behaviors. For example, people differ in the type of advice they seek and utilize (Dalal \& Bonacco, 2010), the extent to which they devalue rewards if there is a delay in their attainment (Odum, 2011), and how they set decision-making goals (Krantz \& Kunreuther, 2007). Research in this area has shed light on the notion that people centrally rely on their expertise and intuition when making decisions (Salas et al., 2010).

In sum, JDM research findings and theories serve as critical informants to identify key decision-making performance behaviors. However, they are not sufficient for comprehensively understanding workplace decision making because workplace decision-making tasks are often ill-defined, fraught with competing goals and feedback loops, and are typically embedded in a hierarchy of tasks (Klein et al., 1993). Thus, workplace decision-making researchers should use multiple types of performance data (choice, behaviors, perceptions, objective outcomes) to assess the various dimensions of workplace decision making. One scale that exists in organizational science is a self- and peer-rating scale that focused on various reactions and perceptions of decision quality (Wood \& Highhouse, 2014). Objective performance indicators (e.g., revenue) and outcomes of the decision (e.g., increased turnover) will also be critical to fully understand the phenomenon.

\section{Mapping Individual Differences Predictors}

The second step involved in predicting decision-making performance is to identify the predictor constructs that conceptually map onto the decision-making performance domain, the development of which we defined as the first step in understanding workplace decision making (Borman et al., 2014; Hough \& Ones, 2001; Schneider et al., 1996). We discuss two categories of relevant predictors and their significance in understanding decision-making behavior: distal and proximal antecedents.

Distal antecedents. Distal antecedents include indi- vidual difference constructs that are relatively stable characteristics of people, such as their cognitive, conative, and affective attributes.

Cognitive predictors. Cognitive abilities can explain one's ability to process any information needed to make decisions (Corno et al., 2002). Cognitive abilities (e.g., reasoning, verbal, quantitative) refer to the mental capacity people have to inductively and deductively reason with various forms of information (Carroll, 1993; Reeve \& Bonaccio, 2011). As Reeve et al. (2015, p. 3) explain, cognitive abilities manifest "behaviorally as the ability to obtain and understand information (i.e., to learn), process information (i.e., reason), and use information to make appropriate decisions (i.e., solve problems in context)." For example, quantitative reasoning (one's capacity to reason with numerical information) influences decisions that involve analysis of data such as a patients' interpretation of statistical information related to treatment (Brunyé et al., 2018). Another study found that spatial ability (one's capacity to process and manipulate visual information) influenced decision making in navigation and wayfinding (Lipkus et al., 2012).

Conative predictors. Conative attributes (i.e., desires, motivations, preferences, behavioral tendencies) influence where people direct behavior, expend effort, the intensity of the effort, and the duration of the effort (Blais et al., 2005; Corno et al., 2002; Levin et al., 2000; Schwartz et al., 2002; Weber \& Johnson, 2009). For example, Scott and Bruce (1995) defined five types of decision styles - rational, intuitive, spontaneous, avoidant, dependent - that describe the manner in which people approach decision making. Magee and Langner (2008) found that an individual's power motivation led to antisocial decisions if self-serving, but if the power motivation was other serving, it led to prosocial decisions. When people make decisions they also differ in the extent to which they satisfice (i.e., pursuing a "good enough" option) or maximize (pursuing the best option), referred to as maximizing tendency (Diab et al., 2008; Iyengar et al., 2006; Schwartz et al., 2002). People who are high in delay discounting - the tendency to devalue rewards if they are not immediate - are more likely to place a lesser value on outcomes that take longer to reach and more value on outcomes that appear in shorter time frames (Kirby et al., 1999; 2005; Odum, 2011; Young, 2017). Indecisiveness, the tendency to postpone making the decision, can lead to negative consequences where the speed of decision is valued and needed in the decision-making process (Shortland et al., 2018).

Affective predictors. Affective attributes influence how people make decisions by directing attention, shaping how feedback is interpreted, and determining which information gets encoded (Starcke \& Brand, 2012; Weber \& Johnson, 2009). For example, mood can influence whether decision-makers focus attention on the disadvantages or advantages when choosing amongst alternative options (Chou et 
al., 2007). Emotions such as anger or fear can reduce the time spent making the decision (George \& Dane, 2016; Weber \& Johnson, 2009). Stress is another significant emotional response that can alter how people make decisions by speeding up the decision process (Driskell \& Salas, 1991; Starcke \& Brand, 2012; 2016).

Proximal antecedents. Proximal antecedents are different from distal antecedents in two ways. First, they are not exogenous factors (i.e., causal variables) but rather are endogenous factors (i.e., caused by other variables) that can be learned, acquired, and improved over time (Byrnes, 2011). Proximal antecedents are determined by cognitive ability, interests, conative attributes, and other exogenous factors (Ackerman, 1996; Corno et al., 2002). Second, proximal antecedents are domain specific; they do not generally apply to all situations. For instance, knowledge of accounting principles is only useful for tasks related to managing finances.

Knowledge and skills. Knowledge and skills are central to decision making. Over time, as individuals gain experience, they are able to identify appropriate responses, and through practice, they gain mastery (Ericsson, 2008). Acquiring knowledge can reduce the time it takes to make a decision because individuals are able to generate rapid, adequate actions with diminishing effort (Jensen, 1998). Expertise, which is an accumulated wealth of knowledge on a specific topic, is central to decision making because people rely on their experience (Klein et al., 1993). However, expertise can harm decision making, as experts are more overconfident and more likely than nonexperts to rely on heuristics or mental rules of thumb (Farrington-Darby \& Wilson, 2006; Shanteau, 1992).

Although central to decision making and conceptually appealing, several scientific disadvantages of measuring knowledge and skills in research exist, including a dearth of construct validity studies (Dalal \& Brooke, 2014), poor psychometric properties, and evidence of construct redundancy (Blacksmith, Behrend, et al., 2019; Blacksmith, Yang, et al., 2019; Reeve \& Basalik, 2011). Furthermore, they often lack explanatory power, which can be both theoretically and methodologically problematic for advancing our understanding of why people make decisions (Corno et al., 2002; Reeve et al., 2015). As such, researchers have advocated for a focus on distal antecedent constructs with established validity evidence instead of directly assessing skills when predicting workplace phenomena (e.g., Reeve et al., 2015). We discuss this approach in more detail below.

\section{Investigating the Complex Predictor Space}

Both the criterion and predictor spaces for workplace decision making are complex and contain numerous constructs. We propose that researchers ought to treat decision performance (behaviors) as the criteria in a process-based mediation model, where relatively stable individual differences (distal antecedents) impact knowledge and skill acquisition (proximal antecedents), which in turn influence decision performance (behavior). Decision performance can also be moderated by task or environmental characteristics (Ackerman, 1996; Klein et al., 1993; Reeve et al., 2015). This approach is grounded in "metatheories" of aptitude that provide a more comprehensive understanding of aptitude by integrating various domains of differential psychology (Reeve et al., 2015). An aptitude is formally defined as the "degree of readiness to learn and to perform well in a particular situation or domain" (Corno et al., 2002, p. 3). Metatheories of aptitude include Ackerman's (1996) intelligence as process, personality, interests, and intelligence as knowledge (PPIK), and Chamorro-Premuzic and Furnham's (2005) intellectual competence theory. PPIK theory hypothesizes that abilities, interests, and personality develop concurrently and give rise to knowledge structures (Ackerman, 1996). For example, individuals higher in mental ability will likely be interested in complex domains such as science, and their personality will act as a motivator to acquire scientific knowledge.

Chamorro-Premuzic and Furnham's (2005) intellectual competence theory posits that aptitude is developed in a manner that relies on the individual's combination of cognitive, affective, and conative traits as fundamental determinants. Combinations of individual differences have been referred to as compound traits, which are linear combinations of personality variables (Credé et al., 2016), and construct constellations, which include a broader range of individual differences constructs such as ability or affect (Reeve et al., 2015).

\section{Methodological Approaches}

Despite the various theories (e.g., PPIK, intellectual competence theory) surrounding construct constellations, the methods used to test these theories lag behind. Organizational science has largely mastered the use of methods that analyze relationships among individual variables and dimensions (i.e., variable-oriented approach; Magnusson \& Stattin, 2006), but the use of methods to study the relationship among combinations of constructs (i.e., pattern-oriented or person-oriented approach) occurs infrequently.

Cluster analytic methods are one way to study combinations of constructs. There are numerous types of cluster analysis, including partition based, hierarchical, fuzzy, density based, and model based (e.g., Chen et al., 1998; Fraley \& Raferty, 1999; Sander et al., 1998). The purpose of cluster analyses is to identify clusters or sets of variables for different purposes, such as dimension reduction/preprocessing, identifying similarities among data points, identifying patterns, or uncovering subgroups (Aldenderfer \& Blashfield, 1984; Romesburg, 2004). This is typically done by using a distance metric (e.g., euclidian) in order to max- 
imize similarity among sets of data points within clusters and to maximize differences between clusters.

Of particular interest for this paper are model-based cluster approaches, specifically mixture models. A detailed discussion of the different types of mixture models is beyond the scope of this paper. Thus, we focus on two types we believe are particularly relevant for the study of decision making: latent profile analysis (LPA) for continuous data and latent class analysis (LCA) for categorical data. LPA and LCA differ from classic cluster analysis methods in that they assume the existence of underlying, latent subpopulations that give rise to the observed data (Oberski, 2016). They also differ in that they are model-based approaches that produce fit estimates of profiles/classes and then classify individuals based on relative probability estimates only after the profiles or classes have been identified (Foti \& McCusker, 2017). That is, latent profiles/classes of individuals with similar patterns of dimensions are identified and organized into meaningful subgroups based on the relative probability that an individual belongs to a particular subgroup (Bergman \& Wångby, 2014).

LPA and LCA are often referred to as pattern-oriented methods, and although they are used rarely in the organizational sciences, they can address many of the concerns we have discussed in this paper thus far (Lanza \& Collins, 2006). Compared to variable-oriented methods, where the unit of analysis is a single variable score, the unit of analysis in pattern-oriented methods is a profile or class representing a latent subgroup assigned to an individual based on a probability calculated from the combination of scores on multiple variables (Meyer et al., 2013). Although we recognize that pattern-oriented and variable-oriented approaches differ both theoretically and methodologically (Bergman \& Trost, 2006), for the purpose of this paper, we focus on the techniques' methodological aspects (see Foti \& McCusker, 2017 for a review of the theory-method distinction). Instead of focusing on the relationships between individual variables and outcomes, pattern-oriented approaches focus on the relationships between sets of variables and outcomes. They are aligned with research examining inherently complex constructs, where sets of variables (i.e., constellations) interact to produce relationships, constructs, or processes that are substantively different from the individual variables alone. This is precisely why pattern-oriented methods, such as LPA and LCA, are used to study individuals (most commonly outside of the organizational sciences), because they assume individuals are intricate systems of interdependent components interacting in a dynamic and complex fashion both with each other and with the system's environment.

If we want to study and predict the complex behavioral processes of decision making, we ought to study the individual holistically (Bergman \& Magnusson, 1997), as an idiosyncratic decision maker. That is, instead of a piecemeal approach that focuses on the bivariate correspondence between individual predictors and outcomes, a unified, parsimonious approach would involve studying multiple constructs in conjunction with each other to see how they collectively interact with each other and the environment to impact decision-making behavior.

We envision at least three ways that pattern-oriented methods can be used in modeling of the decision-making aptitude framework we proposed. The first way is to identify patterns of distal antecedents and relate them to decision-making performance. Whereas a variable-oriented approach might examine the individual relationships between each of the Big Five personality factors and individual decision-making behaviors, for example, a pattern-oriented approach might classify individuals into decision-maker profiles or classes based on their scores on all five factors and relate them to decision-making criteria. This would allow for critical insight into the relationship between a person's personality as a whole and decision-making performance. A relevant example comes from leadership research, where pattern-oriented approaches are occasionally used to study leaders more holistically. In one study, Parr and colleagues (2016) used LCA to uncover six classes of leaders based on their scores on the Big Five. The authors then examined the relationship between the classes and leadership performance. While they found some classes of leaders (e.g., "Power Players") performed relatively high on all the performance dimensions, certain classes performed very high on some dimensions and very low on others (e.g., "Conscientious, Backend Leaders," who perform particularly well in defining the strategy, but poorly in building partnerships). Applied to decision making, scores on the Big Five could be used to uncover classes of decision makers and relate the classes to decision-making performance to understand how different types of personality classes impact decision making.

The second approach involves uncovering profiles or classes of construct constellations that represent decision-making aptitude, one's readiness to learn and perform well in decision-making tasks. Pattern-oriented approaches would allow researchers to treat decision-making aptitude, not as a unitary latent construct but rather a multidimensional, domain-specific construct that represents a collection of interconnected skills or traits in executing a sequence of processes required to reach a choice, judgment, or solution (Corno et al., 2002; Reeve et al., 2015).

The third way LPA and LCA could be used within the decision-making framework we have presented is by uncovering classes or profiles of decision-making behaviors. For example, in a study examining domestic decision making in Kenya, Musalia (2018) uncovered three classes of household decision makers: "egalitarian," "independent," and "conservative." These classes were formed based on the degree to which the decision-making behaviors were distributed in the households across partners. The authors then iden- 
tified several antecedent variables (e.g., education levels, geographic locale, partner's education level, occupation, and wealth index) that predicted whether they belonged to the egalitarian, independent, or conservative class. In other words, they sought to examine the antecedents of each class of decision makers. A different study uncovered profiles based on the behaviors leaders used to lead. They found that different leader behavior patterns differentially impacted perceived leader effectiveness, as determined by subordinate satisfaction and commitment (O'Shea et al., 2009). This similar logic may be applied to the decision-making space by uncovering profiles or classes of decision makers based on a constellation of decision-making behaviors. For example, someone who never seeks advice, frequently devalues outcomes if they are delayed, and always makes decisions quickly may classify into an "intuitive" decision maker and someone who rarely seeks advice, frequently devalues outcomes if they are delayed, and never makes decisions quickly may classify as a "lax" decision maker. The decision-maker profiles or classes may then be put into a model to identify predictors and outcomes associated with each profile or class, as did Gabriel et al. (2015) in a study on emotional labor. Using LPA/LCA, the authors uncovered subpopulations of employees with differing emotional labor profiles (i.e., non-actors, low actors, surface actors, deep actors, regulators) and identified affective factors predicting profile membership, as well as job-related employee outcomes resulting from them.

Another advantage of LPA is that it statistically accounts for interactionism and context. Instead of modeling the traditional two-way interactions of individual differences (e.g., Bakken et al., 2017), for instance, the logic of pattern-oriented approaches lies in modeling the interactions of the individual differences that comprise the defined construct constellation on a continuum. This more closely resembles the natural patterning of decision-making aptitude and allows for the modeling of situations and contexts with the whole individual. Modeling a series of trait by situation interactions can produce complicated and unrealistic results from which practical implications may be difficult to draw. For example, rather than intervening to develop or train employees on a single decision-making dimension, organizations are likely better served by developing tailored learning and training opportunities that target decision-maker profiles.

Longitudinal extensions of LPA and LCA can help researchers better understand how decision-making aptitude can change over time as a function of various situational factors, as well as how different patterns of trajectories can impact individual and organizational outcomes. Examples of longitudinal pattern-oriented approaches include repeated measures latent profile/class analysis (RMLCA/RMLPA; Collins \& Lanza, 2010), latent class growth analysis (LCGA; Sterba \& Bauer, 2010), growth mixture modeling
(GMM; Wang \& Bodner, 2007), and latent transition analysis (LTA; Collins \& Lanza, 2010).

Complex systems and processes such as decision making involve multiple components simultaneously interacting over time and can be explained by a finite set of organizing patterns (Schneider \& Somers, 2006; Uhl-Bien et al., 2007). By studying patterns, or constellations, of constructs, we can move one step closer to modeling and predicting effective decision making at a holistic level rather than at the isolated test-at-a-time score level. It should be noted that although we advocate for the use of LPA and LCA to address decision-making concerns, as with any other analytical technique, it is not without its limitations. LPA and LCA have been criticized for their challenges in the replication of profiles due to sampling differences, low statistical power, and the researchers' interpretation of the number of classes. Thus, it is even more important that researchers ground the selection of the constellation of variables they select in well-established decision-making theory.

\section{Conclusion}

There exist significant opportunities for organizational sciences to contribute to JDM research and stimulate new theory building in a variety of organizational domains, including career decisions, team decision making, strategic planning, entrepreneurship, and leadership effectiveness. By incorporating a holistic person-level measurement approach with a better definition of the decision-making criterion space, we propose that decision-making aptitude (as a constellation of constructs) may be useful as a pre-employment predictor or as a means to assess decision-making readiness and processes. Prioritizing research that examines holistic patterns of decision making and its underlying process would place organizational science in an optimal position to help organizations build and improve the decision-making capacity of leaders and employees.

\section{REFERENCES}

Ackerman, P. L. (1996). A theory of adult intellectual development: Process, personality, interests, knowledge. Intelligence, 22, 227-257. https://doi.org/10.1016/S01602896(96)90016-1

Aldenderfer, M. S., \& Blashfield, R. K. (1984). Cluster analysis. Sage. https://doi.org/10.4135/9781412983648

Appelt, K. C., Milch, K. F., Handgraaf, M. J. J., \& Weber, E. U. (2011). The decision making individual differences inventory and guidelines for the study of individual differences in judgment and decision-making research. Judgment and Decision Making, 6, 252-262.

Anderson, N. H. (1971). Integration theory and attitude change. Psychological Review, 78, 171-206. https://doi.org/10.1037/ h0030834

Bakhshi, H., Downing, J. M., Osborne, M. A., \& Schneider, P. (2017). 
The future of skills employment in 2030. Pearson. https:// futureskills.pearson.com/research/assets/pdfs/technical-report.pdf

Bakken, B. T., Hansson, M., \& Haerem, T. (2017). Interaction effects of intuitive and analytic cognitive styles on decision making performance. Academy of Management Proceedings, 1, 14419. https://doi.org/10.5465/ambpp.2016.14419abstract

Bazerman, M. H., \& Moore, D. A. (2013). Judgment in managerial decision making. John Wiley \& Sons, Inc.

Beach, L. R. (1996). Decision making in the workplace: A unified perspective. Lawrence Erlbaum Associates, Inc.

Bergman, L. R., \& Magnusson, D. (1997). A person-oriented approach in the research on developmental psychopathology. Development and Psychopathology, 9, 291-319. https://doi. org/10.1017/S095457949700206X

Bergman, L. R., \& Trost, K. (2006). The person-oriented versus the variable-oriented approach: Are they complementary, opposites, or exploring different worlds? Merrill-Palmer Quarterly, 52, 601-632. https://doi.org/10.1353/mpq.2006.0023

Bergman, L. R., \& Wångby, M. (2014). The person-oriented approach: A short theoretical and practical guide. Eesti Haridusteaduste Ajakiri, 2, 29-49. https://doi.org/10.12697/ eha.2014.2.1.02b

Binning, J. F., \& Barrett, G. V. (1989). Validity of personnel decisions: A conceptual analysis of the inferential and evidential bases. Journal of Applied Psychology, 74, 478-494. https:// doi.org/10.1037/0021-9010.74.3.478

Blais, A., Thompson, M. M., \& Baranski, J. V. (2005). Individual differences in decision processing and confidence judgments in comparative judgment tasks: The role of cognitive styles. Personality and Individual Differences, 38, 1701-1713. https://doi.org/10.1016/j.paid.2004.11.004

Blacksmith, N., Behrend, T. S., Dalal, R. S., \& Hayes, T. L. (2019). General mental ability and decision-making competence: Theoretically distinct but empirically redundant. Personality and Individual Differences, 138, 305-311. https://doi. org/10.1016/j.paid.2018.10.024

Blacksmith, N., Yang, Y., Behrend, T. S., \& Ruark, G. A. (2019). Assessing the validity of inferences from scores on the cognitive reflection test. Journal of Behavioral Decision Making, 32, 599-612. https://doi.org/10.1002/bdm.2133

Borman, W. C., \& Brantley, L. B., \& Hanson, M. A. (2014). Progress toward understanding the structure and determinants of job performance: A focus on task and citizenship performance. International Journal of Selection and Assessment, 22, 422-431. https://doi.org/10.1111/ijsa.12088

Borman, W. C., Hanson, M. A., \& Hedge, J. W. (1997). Personnel selection. Annual Review of Psychology, 48, 299-337. https:// doi.org/10.1146/annurev.psych.48.1.299

Brunyé, T. T., Gardony, A. L., Holmes, A., \& Taylor, H. A. (2018). Spatial decision dynamics during wayfinding: Intersections prompt the decision-making process. Cognitive Research: Principles and Implications, 3, 13. https://doi.org/10.1186/ s41235-018-0098-3

Byrnes, J. P. (2011). The nature and development of decision making: A self-regulation model. Routledge.

Campbell, J. P., Gasser, M. E., \& Oswald, F. L. (1996). The substantive nature of job performance. In K. R. Murphy (Ed.), Individual differences and behavior in organizations ( $p$.
258-299). Jossey-Bass.

Campbell, J. P., \& Wiernik, B. M. (2015). The modeling and assessment of work performance. Annual Review of Organizational Psychology and Organizational Behavior, 2, 47-74. https:// doi.org/10.1146/annurev-orgpsych-032414-111427

Carroll, J. B. (1993). Human cognitive abilities: A survey of factor-analytic studies. Cambridge University Press. https://doi. org/10.1017/CBO9780511571312

Chamorro-Premuzic, T., \& Furnham, A. (2005). Intellectual competence. Psychologist, 18, 352-354.

Chen, J. Q., Xi, Y. G., \& Zhang, Z. J. (1998). A clustering algorithm for fuzzy model identification. Fuzzy Sets and Systems, 98, 319-329. https://doi.org/10.1016/S0165-0114(96)00384-3

Chou, K. L., Lee, T., \& Ho, A. H. (2007). Does mood state change risk taking tendency in older adults? Psychology and Aging, 22, 310-318. https://doi.org/10.1037/0882-7974.22.2.310

Collins, L. M., \& Lanza, S. T. (2010). Latent class and latent transition analysis: With applications in the social, behavioral, and health sciences (Vol. 718). John Wiley \& Sons.

Corno, L., Cronbach, L. J., Kupermintz, H., Lohman, D. F., Mandinach, E. B., Porteus, A. W., \& Talbert, J. E. (2002). Remaking the concept of aptitude: Extending the legacy of Richard. E. Snow. Erlbaum. https://doi.org/10.4324/9781410604521

Credé, M., Harms, P. D., Blacksmith, N., \& Wood, D. (2016). Assessing the utility of compound trait estimates of narrow personality traits. Journal of Personality Assessment, 98, 503513. https://doi.org/10.1080/00223891.2016.1170023

Dalal, R. S., \& Bonaccio, S. (2010). What types of advice do decision-makers prefer? Organizational Behavior and Human Decision Processes, 112, 11-23. https://doi.org/10.1016/ j.obhdp.2009.11.007

Dalal, R. S., \& Brooks, M. E. (2014). Individual differences in decision-making skill and style. In S. Highhouse, R. S. Dalal, \& E. Salas (Eds.), Judgment and decision making at work (pp. 88101). Taylor \& Francis.

Diab, D. L., Gillespie, M. A., \& Highhouse, S. E. (2008). Are maximizers really unhappy? The measurement of maximizing tendency. Judgment and Decision Making, 3, 364-370. https://doi.org/10.1037/t45820-000

Driskell, J. E., \& Salas, E. (1991). Group decision making under stress. Journal of Applied Psychology, 3, 473-478. https:// doi.org/10.1037/0021-9010.76.3.473

Ericsson, K. A. (2008). Deliberate practice and acquisition of expert performance: A general overview. Academic Emergency Medicine, 15, 988-994. https://doi.org/10.1111/j.15532712.2008.00227.x

Evans, J. S. B. (2008). Dual-processing accounts of reasoning, judgment, and social cognition. Annual Review Psychology, 59, 255-278. https://doi.org/10.1146/annurev. psych.59.103006.093629

Farrington-Darby, T., \& Wilson, J. R. (2006). The nature of expertise: A review. Applied Ergonomics, 37, 17-32. https://doi. org/10.1016/j.apergo.2005.09.001

Foti, R. J., \& McCusker, M. E. (2017). Person-oriented approaches to leadership: A roadmap forward. In B. Schyns, R. J. Hall, \& P. Neves (Eds.), Handbook of methods in leadership research. Edward Elgar Publishing.

Fraley, C., \& Raftery, A. E. (1999). MCLUST: Software for model-based cluster analysis. Journal of Classification, 16, 297- 
306. https://doi.org/10.1007/s003579900058

Gabriel, A. S., Daniels, M. A., Diefendorff, J. M., \& Greguras, G. J. (2015). Emotional labor actors: A latent profile analysis of emotional labor strategies. Journal of Applied Psychology, 100, 863-879. https://doi.org/10.1037/a0037408

George, J. M., \& Dane, E. (2016). Affect, emotion, and decision-making. Organizational Behavior and Human Decision Processes, 136, 47-55. https://doi.org/10.1016/j.obhdp.2016.06.004

Gigerenzer, G., \& Gaissmaier, W. (2011). Heuristic decision making. Annual Review of Psychology, 62, 451-482. https://doi. org/10.1146/annurev-psych-120709-145346

Guion, R. M. (2011). Assessment, measurement, and prediction for personnel decisions. Routledge. https://doi. org/10.4324/9780203836767

Harvey, A., \& Woodruff, M. J. (2013). Confirmation bias in the United States Supreme Court judicial database. Journal of Law, Economics, \& Organization, 29, 414-460. https://doi. org/10.1093/jleo/ewr003

Hastie, R., \& Dawes, R. M. (2001). Rational choice in an uncertain world. The psychology of judgment and decision-making. Sage Publications, Inc.

Hays. (2018). Investing in the skills of tomorrow: Avoiding a spiraling skills crisis. https://www.hays-index.com/wp-content/ uploads/2018/09/Hays-Global-Skills-Index-2018-Report.pdf

Highhouse, S. E., Dalal, R. S., \& Salas, E. (2014). Judgment and decision making at work. Taylor \& Francis. https://doi. org/10.4324/9780203767054

Hough, L. M., \& Ones, D. S. (2001). The structure measurement, validity, and use of personality variables in industrial work, and organizational psychology. In N. Anderson, D. S. Ones, H. K. Sinangil, \& C. Viswesvaran (Eds.), Handbook of industrial work, and organizational psychology (Volume 1.). Sage.

IBM. (2016). Facing the storm: Navigating the global skills crisis. https://www.ibm.com/downloads/cas/LBMPLMLJ

Industrial Strategy Council. (2019). U.K. Skills mismatch in 2030. https://industrialstrategycouncil.org/sites/default/files/ UK\%20Skills\%20Mismatch\%202030\%20-\%20Research\%20 Paper.pdf

lyengar, S. S., Wells, R. E., \& Schwartz, B. (2006). Doing better but feeling worse: Looking for the "best" job undermines satisfaction. Psychological Science, 17, 143-150. https://doi. org/10.1111/j.1467-9280.2006.01677.x

Jensen, A. R. (1998). The $g$ factor: The science of mental ability. Praeger.

Kahneman, D. (2011). Thinking fast and slow. Farrar, Straus, and Giroux.

Kahneman, D., \& Tversky, A. (1979). Prospect theory: An analysis of decision under risk. Econometrica, 47, 263-291. https:// doi.org/10.2307/1914185

Kirby K. N., Petry N. M., \& Bickel W. K. (1999). Heroin addicts have higher discounting rates for delayed rewards than non-drug-using controls. Journal of Experimental Psychology: General, 128, 78-87. https://doi.org/10.1037/00963445.128.1.78

Kirby K. N., Winston G. C., \& Santiesteban M. (2005). Impatience and grades: Delay-discount rates correlate negatively with college GPA. Learning and Individual Differences, 15, 213222. https://doi.org/10.1016/j.lindif.2005.01.003
Klein, G. (2008). Naturalistic decision making. Human Factors, 50, 456-460. https://doi.org/10.1518/001872008X288385

Klein, G., \& Klinger, D. (1991). Naturalistic decision making. Human Systems IAC Gateway, 11, 16-19.

Klein, G. A., Orasanu, J., Calderwood, R., \& Zsambok, C. E. (Eds.) (1993). Decision making in action: Models and methods. Ablex.

Korn Ferry. (2018). Future of work: The global talent crunch. https://business.linkedin.com/talent-solutions/blog/trendsand-research/2018/industries-biggest-talent-shortages-2030

Krantz, D. H., \& Kunreuther, H. (2007). Goals and plans in decision making. Judgment and Decision Making, 2, 137-168. https://doi.org/10.3386/w12446

Lachter, J., Forster, K. I., \& Ruthruff, E. (2004). Forty-five years after Broadbent 1958: Still no identification without attention. Psychological Review, 111, 880-913. https://doi. org/10.1037/0033-295X.111.4.880

Lanza, S. T., \& Collins, L. M. (2006). A mixture model of discontinuous development in heavy drinkers from ages 18-30: The role of college enrollment. Journal of Studies in Alcohol, 67, 552-561. https://doi.org/10.15288/jsa.2006.67.552

Levin, I. P., Huneke, M. E., \& Jasper, J. D. (2000). Information processing at successive stages of decision-making: Need for cognition and inclusion-exclusion effects. Organizational Behavior and Human Decision Processes, 82, 171-193. https://doi.org/10.1006/obhd.2000.2881

Lipkus, I. M., Peters, E., Kimmick, G., Liotcheva, V., \& Marcom, P. (2012). Breast cancer patients' treatment expectations after exposure to the decision aid program. Medical Decision Making, 30, 464-473. https://doi. org/10.1177/0272989X09360371

Magee, J. C., \& Langner, C. A. (2008). How personalized and socialized power motivation facilitate antisocial and prosocial decision-making. Journal of Research in Personality, 42, 1547-1559. https://doi.org/10.1016/j.jrp.2008.07.009

Magnusson, D., \& Stattin, H. (2006). The person in context: A holistic-interactionistic approach. In R. M. Lerner, \& W. Damon (Eds.), Handbook of child psychology: Vol 1.Theoretical models of human development (6th ed., pp. 404-464). John Wiley \& Sons, Inc. https://doi.org/10.1002/9780470147658. chpsy0108

McKinsey Global Institute. (2018). Skill shift automation and the future of the workforce. https://www.mckinsey.com/ / media/McKinsey/Featured\%20Insights/Future $\% 20$ of $\% 20$ Organizations/Skill\%20shift\%20Automation\%20and\%20 the\%20future\%20of\%20the\%20workforce/MGI-Skill-ShiftAutomation-and-future-of-the-workforce-May-2018.ashx

McLaren, S. (2018). These industries will face the biggest talent shortages by 2030. https://business.linkedin.com/ talent-solutions/blog/trends-and-research/2018/industries-biggest-talent-shortages-2030

Meyer, J. P., Stanley, L. J., \& Vandenberg, R. J. (2013). A person-centered approach to the study of commitment. Human Resource Management Review, 23, 190-202. https:// doi.org/10.1016/j.hrmr.2012.07.007

Mitchell, S. H. (2017). Devaluation of outcomes due to their cost: Extending discounting models beyond delay. In J. R. Stevens (Ed.), Impulsivity (Vol. 64, pp. 145-161). Springer In- 
ternational Publishing. https://doi.org/10.1007/978-3-319 51721-6_5

Mohammed, S., \& Schwall, A. (2009). Individual differences and decision making: What we know and where we go from here. International Review of Organizational Psychology, 24, 249-312. https://doi.org/10.1002/9780470745267.ch8

Musalia, J. (2018). Household decision making among married women in Kenya: A latent class analysis. Sex Roles, 78, 182193. https://doi.org/10.1007/s11199-017-0788-1

National Research Council. (2015). Measuring human capabilities: An agenda for basic research on the assessment of individual and group performance potential for military accession. Committee on Measuring Human Capabilities: Performance Potential of Individuals and Collectives, Board on Behavioral, Cognitive, and Sensory Sciences, Division of Behavioral and Social Sciences and Education. National Academies Press.

Oberski, D. (2016). Mixture models: Latent profile and latent class analysis. In J. Robertson \& M. Kaptein (Eds). Modern statistical methods for $\mathrm{HCl}$ (pp. 275-287). Springer. https:// doi.org/10.1007/978-3-319-26633-6_12

Odum, A. L. (2011). Delay discounting: I'm a k, you're a k. Journal of the Experimental Analysis of Behavior, 96, 427-439. https://doi.org/10.1901/jeab.2011.96-423

Oreg, S., \& Bayazit, M. (2009). Prone to bias: Development of a bias taxonomy from an individual differences perspective. Review of General Psychology, 13, 175-193. https://doi. org/10.1037/a0015656

O'Shea, P. G., Foti, R. J., Hauenstein, N. M. A., \& Bycio, P. (2009). Are the best leaders both transformational and transactional? A pattern-oriented analysis. Leadership, 5, 237-259. https:// doi.org/10.1177/1742715009102937

Parr, A. D., Lanza, S. T., \& Bernthal, P. (2016). Personality profiles of effective leadership performance in assessment centers. Human performance, 29(2), 143-157.

Reeve, C. L., \& Basalik, D. (2011). Is health literacy an example of construct proliferation? A conceptual and empirical evaluation of its redundancy with general cognitive ability. Intelligence, 44, 93-102. https://doi.org/10.1016/j.intell.2014.03.004

Reeve, C. L., \& Bonaccio, S. (2011). The nature and structure of "intelligence." In T. Chamorro-Premuzic, A. Furnham, \& S. von Stumm (Eds.), Handbook of individual differences (pp. 187-216). Wiley-Blackwell. https://doi. org/10.1002/9781444343120.ch7

Reeve, C. L., Scherbaum, C., \& Goldstein, H. (2015). Manifestations of intelligence: Expanding the measurement space to reconsider specific cognitive abilities. Human Resource Management Review, 25, 28-37. https://doi.org/10.1016/ j.hrmr.2014.09.005

Romesburg, H. C. (2004). Cluster analysis for researchers. Lulu Press.

Ryan, A. M., \& Ployhart, R. E. (2014). A century of selection. Annual Review of Psychology, 65, 693-717. https://doi. org/10.1146/annurev-psych-010213-115134

Sackett, P. R., Lievens, F., Van Iddekinge, C. H., \& Kuncel, N. R. (2017). Individual differences and their measurement: A review of 100 years of research. Journal of Applied Psychology, 102, 254. https://doi.org/10.1037/apl0000151
Salas, E., Rosen M. A., \& DiazGranados, D. (2010). Expertise-based intuition and decision making in organizations. Journal of Management, 36, 941-973. https://doi. org/10.1177/0149206309350084

Sander, J., Ester, M., Kriegel, H. P., \& Xu, X. (1998). Density-based clustering in spatial databases: The algorithm GBDSCAN and its applications. Data Mining and Knowledge Discovery, 2, 169-194. https://doi.org/10.1023/A:1009745219419

Schneider, M. (2017). Google beats unconscious bias by teaching its employees these 4 tactics. Inc. Magazine. https://www. inc.com/michael-schneider/google-beats-unconscious-bias-by-teaching-its-employees-these-4-tactics.html

Schneider, M., \& Somers, M. (2006). Organizations as complex adaptive systems: Implications of complexity theory for leadership research. Leadership Quarterly, 17, 351-365. https://doi.org/10.1016/j.leaqua.2006.04.006

Schneider, R. J., Hough, L. M., \& Dunnette, M. D. (1996). Broadsided by broad traits: How to sink science in five dimensions or less. Journal of Organizational Behavior, 17, 639-655. https:// doi.org/10.1002/(SICI)1099-1379(199611)17:6\%3C639::AIDJOB3828\%3E3.0.CO;2-9

Schumann, F. (2018). A new solution to the skilled workers shortage. https://www.gallup.com/workplace/240584/newsolution-skilled-workers-shortage.aspx

Schwartz, D., Ward, A., Monterosson, J., Lyubomirsky, S., White, K., \& Lehman, D. R. (2002). Maximizing versus satisficing: Happiness is a matter of choice. Journal of Personality and Social Psychology, 83, 1178-1197. https://doi.org/10.1037/00223514.83.5.1178

Scott, S. G., \& Bruce, R. A. (1995). Decision-making style: The development and assessment of a new measure. Educational and Psychological Measurement, 55, 818-831. https://doi.or $\mathrm{g} / 10.1177 / 0013164495055005017$

Shanteau, J. (1992). The psychology of experts an alternative view. In G. Wright \& F. Bolger (Eds.) Expertise and decision support (pp. 11-23). Springer. https://doi.org/10.1007/9780-585-34290-0_2

Shortland, N., Alison, L., \& Barrett-Pink, C. (2016). Military (in) decision-making process: A psychological framework to examine decision inertia in military operations. Theoretical Issues in Ergonomics Science, 19, 752-772. https://doi.org/1 $0.1080 / 1463922 X .2018 .1497726$

Simon, H. A. (1955). A behavioral model of rational choice. Quarterly Journal of Economics, 69, 99-118.

Simon, H. A. (1978). Rationality as process and as product of thought. American Economic Review, 68, 1-16.

Society for Human Resources Management. (2019). The global skills shortage: Bridging the talent gap with education, training, and sourcing. https://www.shrm.org/hr-today/ trends-and-forecasting/research-and-surveys/Documents/ SHRM\%20Skills\%20Gap\%202019.pdf

Sonnentag, S., \& Frese, M. (2002). Performance concepts and performance theory. In S. Sonnentag (Ed.), Psychological management of individual performance. John Wiley, \& Sons, Ltd. https://doi.org/10.1002/0470013419

Starcke, K., \& Brand, M. (2012). Decision making under stress: A selective review. Neuroscience and Biobehavioral Review, 36, 1228-1248. https://doi.org/10.1016/j.neubiorev.2012.02.003 
Starcke, K., \& Brand, M. (2016). Effects of stress on decision under uncertainty: A meta-analysis. Psychological Bulletin, 142, 909-933. https://doi.org/10.1037/bul0000060

Sterba, S. K., \& Bauer, D. J. (2010). Matching method with theory in person-oriented developmental psychopathology research. Development and Psychopathology, 22, 239-254. https://doi.org/10.1017/S0954579410000015

Tsipursky, G. (2018). Will Starbuck's anti-bias training be effective? Scientific American. https://blogs.scientificamerican. com/voices/will-starbuckss-anti-bias-training-be-effective/

Tversky, A., \& Kahneman, D. (1974). Judgment under uncertainty: Heuristics and biases. Science, 185, 1124-1131. https:// doi.org/10.1126/science.185.4157.1124

Uhl-Bien, M., Marion, R., \& McKelvey, B. (2007). Complexity leadership theory: Shifting leadership from the industrial age to the knowledge era. Leadership Quarterly, 18, 298-318. https://doi.org/10.1016/j.leaqua.2007.04.002

Wang, M., \& Bodner, T. E. (2007). Growth mixture modeling: Identifying and predicting unobserved subpopulations with longitudinal data. Organizational Research Methods, 10, 635-656. https://doi.org/10.1177/1094428106289397

Weber, E. U., \& Johnson, E. J. (2009). Mindful judgment and decision-making. Annual Review of Psychology, 60, 53-85. https://doi.org/10.1146/annurev.psych.60.110707.163633

Wood, N. L., \& Highhouse, S. (2014). Do self-reported decision styles relate with others' impressions of decision quality? Personality and Individual Differences, 70, 224-228. https:// doi.org/10.1016/j.paid.2014.06.036

Young, M. E. (2017). Discounting: A practical guide to multilevel analysis of indifference data. Journal of the Experimental Analysis of Behavior, 108, 97-112. https://doi.org/10.1002/ jeab.265

RECEIVED 05/15/19 ACCEPTED 07/05/20 